\title{
Clinical Features in Juvenile-Onset Ankylosing Spondylitis Patients Carrying Different B27 Subtypes
}

\author{
Yikun Mou, Pingping Zhang, Qiuxia Li, Zhiming Lin, Zetao Liao, \\ Qiujing Wei, and Jieruo Gu \\ Department of Rheumatology, The Third Affiliated Hospital of Sun Yat-Sen University, Guangzhou, Guangdong 510630, China \\ Correspondence should be addressed to Jieruo Gu; gujieruo@163.com
}

Received 27 August 2014; Revised 11 October 2014; Accepted 12 October 2014

Academic Editor: James C. C. Wei

Copyright (c) 2015 Yikun Mou et al. This is an open access article distributed under the Creative Commons Attribution License, which permits unrestricted use, distribution, and reproduction in any medium, provided the original work is properly cited.

\begin{abstract}
Background. Ankylosing spondylitis (AS) is a common rheumatic disease and is characterized by inflammation of the axial skeleton. HLA-B27 is strongly associated with AS. Juvenile-onset AS (JAS) with disease onset before 16 years of age differs from adult-onset AS (AAS) in many respects. Objective. To compare the clinical features in JAS with different B27 subtypes and analyze the differences between JAS and AAS. Methods. 145 JAS and 360 AAS patients were included. The demographic data, clinical manifestations, laboratory markers, Bath AS indices, and B27 subtypes were recorded. Results. Peripheral arthritis, enthesitis, BASDAI, ESR, and CRP were significantly higher in JAS patients with HLA-B*2704 than those with B27-negative. Enthesitis and ESR were significantly higher in patients with HLA-B ${ }^{*} 2705$ than those with B27-negative. The onset age of HLA-B ${ }^{*} 2715$ group was much earlier than the other groups. The peripheral arthritis, enthesitis, and hip joint involvement in JAS with HLA-B ${ }^{*} 2704$ were significantly higher than those in AAS with HLA-B*2704. Conclusion. JAS with different B27 subtypes had similar features in most of manifestations; JAS and AAS patients with the same subtype could have distinctive courses. Early diagnosis, hip detection, and control of systemic active inflammation in JAS patients will be helpful for improving the prognosis.
\end{abstract}

\section{Introduction}

Ankylosing spondylitis (AS) is an inflammatory disorder mainly affecting the axial joints and distinguished by a significant association with HLA-B27 [1,2]. Juvenile-onset AS (JAS), that is, having onset of symptoms before 16 years of age, is the major part of juvenile spondyloarthropathies (JSpA). In China, JAS accounts for $27.8 \% \sim 29.8 \%$ [3, 4]. Because the individual differences in the clinical manifestations are large and sacroiliac joints of children are in the developmental stage, so imaging diagnoses are limited, and diagnosis may be delayed. JAS has different phenotype and prognosis than adult-onset AS (AAS) [5]. Many studies report about clinical features of JAS $[3,6]$, and little about those in JAS patients carries different B27 subtypes.

We suspected whether there was different pathological mechanism in JAS. In our previous studies, a group of JAS patients have been typed into B27 subtypes; the positive rate of B27 subtypes in JAS group had no statistical difference compaired with AAS group [7]. We further analysed the clinical manifestations of JAS with different B27 subtypes in this study, so as to investigate the clinical and pathological mechanism of JAS.

\section{Patients and Methods}

2.1. Patient Population. From June 2005 to April 2013, 145 JAS and 360 AAS outpatients and inpatients registered in rheumatology department of our hospital were included in this study. All the patients fulfilled the modified New York criteria for AS. Patients with the concomitant presence of chronic renal or hepatic disease, blood disorders, endocrine system diseases, and various acute infections or other infectious diseases were excluded.

Informed consent was obtained from each patient involved in the study. 
TABLE 1: Distribution of patients with different B27 subtype and B27negative in JAS and AAS groups.

\begin{tabular}{lccc}
\hline & JAS & AAS & $P$ \\
\hline $\begin{array}{l}\text { HLA-B27- } \\
\text { negative }\end{array}$ & $11 / 145(7.59 \%)$ & $41 / 360(11.39 \%)$ & 1.000 \\
HLA-B 2704 & $120 / 145(82.76 \%)$ & $275 / 360(76.39 \%)$ & 1.000 \\
HLA-B $^{*} 2705$ & $11 / 145(7.59 \%)$ & $38 / 360(10.56 \%)$ & 1.000 \\
HLA-B $^{*} 2715$ & $3 / 145(2.07 \%)$ & $3 / 360(0.83 \%)$ & 1.000 \\
HLA-B $^{*} 2702$ & $0 / 145(0)$ & $3 / 360(0.83 \%)$ & 0.561 \\
\hline
\end{tabular}

2.2. Biochemical Parameters. C reactive protein (CRP) and erythrocyte sedimentation rate (ESR) were measured by standard laboratory methods.

2.3. Baseline Disease Activity Measures. The following measures were obtained at baseline visit: Bath ankylosing spondylitis disease activity index (BASDAI) score $(0=$ none, $10=$ worst $)$ and Bath ankylosing spondylitis functional index (BASFI) score $(0=$ none, $10=$ worst $)$.

2.4. Joint Counts. In the 44 joints, which include bilateral proximal interphalangeal joints, metacarpophalangeal joints, wrist, elbow, shoulder, acromioclavicular, sternoclavicular joint, knee, ankle joints, and metatarsophalangeal joint, the number of joints with swelling and tenderness was recorded.

2.5. Statistical Analysis. Statistical software SPSS 19.0 for Windows was used to analyze data. Normally distributed measurement data was shown as "mean \pm standard deviation," non-normally distributed data as "median (lower quartile-upper quartile)." The original data of BASFI, ESR, and CRP were skewed distribution, respectively, but after logarithmic transformation, the data became normal distribution, and then they were analyzed. The mean values of two independent samples were compared using $t$-test; comparison between multiple groups was analyzed using oneway ANOVA, while pairwise comparisons between groups were analyzed using LSD- $t$ test. Chi-square test was used to analyze constituent ratio. Kruskal-Wallis test was used for comparison in multigroups; Mann-Whitney $U$ test was used for comparison between two groups. Differences were considered significant at $P<0.05$.

\section{Results}

3.1. Characteristics of the JAS and AAS Patients. The mean age of 145 JAS patients, including 136 males and 9 females (male : female $=15.1: 1$ ), was $21.3 \pm 7.6$ years (from 10 to 43 years). Among them, 35 patients were $\leq 16 \mathrm{y}$ and $110>16 \mathrm{y}$. The onset age was 5 to 16 years, and the average onset age was $13.49 \pm 2.36$ years. The median duration of disease was 6 years (0.04 to 27 years). 104 patients were sporadic and 41 individuals had family histories (sporadic cases: cases with family histories $=2.54$ ). Mean age of the 360 AAS patients (306 male, 54 female) was $30.5 \pm 7.6$ years, with mean duration of disease $6.9 \pm 5.7$ years ( 0.3 to 35 years).
3.2. Comparison of the B27 Subtype Distribution and Clinical Phenotype between JAS and AAS Groups. There was no significant difference in distribution of B27-negative patients and different B27 subtypes between JAS and AAS groups, shown in Table 1 . The preliminary study of our research team has shown no significant difference in the constituent ratio of B27 subtypes between the two groups [7], and in the present study B27-negative patients were brought into this table, and there was also no significant difference in the distribution between JAS and AAS groups.

3.3. Comparison of Clinical Features between Different B27 Subtypes in the JAS Group. Because the data of BASFI, ESR, and CRP was not normally distributed, comparison was done after logarithmic transformation. As shown in Tables 2 and 3, there was no significant difference in the diagnostic age, male preponderance, family histories, hip arthritis, iridocyclitis, and BASFI among the four different groups in JAS patients. Peripheral arthritis, enthesitis, BASDAI, ESR, and CRP were significantly higher in patients with HLA-B* 2704 than in those with B27-negative. Enthesitis and ESR were significantly higher in patients with HLA-B* 2705 than in those with B27-negative. The Incidence of waxy digitus was more common in HLA-B* 2705 group than that in HLA-B* 2704 group. The onset age of HLA-B ${ }^{*} 2715$ group $(5,9$, and 13 years) was much earlier than that in the other three groups.

3.4. Comparison of Clinical Features between JAS and AAS Groups. The group of JAS had higher male preponderance than AAS. And peripheral arthritis, enthesitis, and hip arthritis were more common in patients with JAS than AAS, shown in Table 4.

3.5. Comparison of Clinical Features in JAS and AAS Patients with $H L A-B^{*} 2704$ and $H L A-B^{*} 2705$. The comparison of clinical features in JAS and AAS patients with HLA-B* 2704 and HLA-B* 2705 was shown in Table 5. In patients with HLA-B ${ }^{*} 2704$, male preponderance was more obvious in JAS, and peripheral arthritis, enthesitis, and hip arthritis were also more common in JAS patients. There was no significant difference in these indicators between JAS and AAS patients with HLA-B* 2705.

\section{Discussion}

Among JAS patients with HLA-B*2704, HLA-B*2705, and HLA-B ${ }^{*} 2715$, there were no significant difference in male ratio, positive family history, peripheral arthritis, enthesitis, hip arthritis, iridocyclitis, and indicators, for example, BASDAI, BASFI, ESR, and CRP, which showed that the pathogenesis of different subtypes might be similar.

In the comparison between JAS patients with HLAB27-positive and HLA-B27-negative, patients with peripheral arthritis and enthesitis in the HLA-B27-negative group were less than those in HLA-B*2704 group; the inflammatory indicators, such as BASDAI, ESR, and CRP, in patients with HLA-B27-negative were lower than those in patients with HLA-B ${ }^{*} 2704$, which indicated the milder level of inflammation in HLA-B27-negative patients. Our previous research on 
TABLE 2: Comparison of clinical features, Bath AS indices, and inflammatory markers in JAS patients with B27-negative and different B27 subtypes.

\begin{tabular}{|c|c|c|c|c|c|c|c|}
\hline $\begin{array}{l}\text { HLA-B27 } \\
\text { subtype }\end{array}$ & Age (y) & Onset age (y) & $\begin{array}{c}\text { Disease } \\
\text { duration }(\mathrm{y})\end{array}$ & $\begin{array}{l}\text { BASDAI } \\
\text { (score) }\end{array}$ & $\begin{array}{l}\text { BASFI } \\
\text { (score) }\end{array}$ & $\begin{array}{c}\text { ESR } \\
(\mathrm{mm} / \mathrm{h})\end{array}$ & $\begin{array}{c}\text { CRP } \\
(\mathrm{mg} / \mathrm{L})\end{array}$ \\
\hline $\begin{array}{l}\text { HLA-B27- } \\
\text { negative }\end{array}$ & $\begin{array}{c}18.09 \pm 3.65 \\
(n=11)\end{array}$ & $\begin{array}{c}14.09 \pm 2.11 \\
(n=11)\end{array}$ & $\begin{array}{c}4.01 \pm 4.39 \\
(n=11)\end{array}$ & $\begin{array}{c}2.05 \pm 1.42 \\
(n=11)\end{array}$ & $\begin{array}{c}1.55(1.21,3.43) \\
(n=8)\end{array}$ & $\begin{array}{c}7.00(4.00,9.40) \\
(n=11)\end{array}$ & $\begin{array}{c}1.10(0.60,5.00) \\
(n=7)\end{array}$ \\
\hline HLA-B ${ }^{*} 2704$ & $\begin{array}{c}21.79 \pm 8.02 \\
(n=120)\end{array}$ & $\begin{array}{c}13.54 \pm 2.31 \\
(n=120)\end{array}$ & $\begin{array}{l}8.25 \pm 8.06 \\
(n=120)\end{array}$ & $\begin{array}{c}4.22 \pm 1.95^{*} \\
(n=112)\end{array}$ & $\begin{array}{c}3.00(1.90,5.20) \\
\quad(n=112)\end{array}$ & $\begin{array}{c}32.00(14.00,48.75)^{*} \\
(n=120)\end{array}$ & $\begin{array}{c}18.55(5.9 \\
49.78)^{*} \\
(n=120)\end{array}$ \\
\hline HLA-B* 2705 & $\begin{array}{l}18.36 \pm 3.96 \\
(n=11)\end{array}$ & $\begin{array}{c}13.55 \pm 1.77 \\
(n=11)\end{array}$ & $\begin{array}{c}4.82 \pm 4.46 \\
(n=11)\end{array}$ & $\begin{array}{c}3.61 \pm 1.26 \\
(n=9)\end{array}$ & $\begin{array}{c}1.6(1.00,4.20) \\
(n=9)\end{array}$ & $\begin{array}{c}14.0(7.00,48.00)^{*} \\
(n=11)\end{array}$ & $\begin{array}{c}5.80(1.45,34.30) \\
\quad(n=11)\end{array}$ \\
\hline HLA-B ${ }^{*} 2715$ & $\begin{array}{c}24.33 \pm 6.43 \\
(n=3)\end{array}$ & $\begin{array}{c}9.00 \pm 4.00^{* \# a} \\
(n=3)\end{array}$ & $\begin{array}{c}15.33 \pm 4.16^{* a} \\
(n=3)\end{array}$ & $\begin{array}{c}3.28 \pm 2.79 \\
\quad(n=2)\end{array}$ & $\begin{array}{c}1.125(1.00,1.25) \\
(n=2)\end{array}$ & $\begin{array}{c}65.00(4.00,135.00)^{*} \\
(n=3)\end{array}$ & $\begin{array}{c}15.53(1.50, \\
113.45) \\
(n=3)\end{array}$ \\
\hline
\end{tabular}

Note: (1) data in the table was mean \pm standard deviation or median (upper quartile, lower quartile); (2) ${ }^{*}$ comparison between groups of different B27 subtypes and group of B27-negative, $P<0.05$; $(3)^{\#}$ comparison between HLA-B ${ }^{*} 2715$ and HLA-B ${ }^{*} 2704$ group, $P<0.05$; $(4)^{\text {a }}$ comparison between HLA-B 2715 and HLA-B ${ }^{*} 2705$ group, $P<0.05$.

TABLE 3: Comparison of clinical features in JAS patients with B27-negative and different B27 subtypes.

\begin{tabular}{|c|c|c|c|c|c|c|c|}
\hline $\begin{array}{l}\text { HLA-B27 } \\
\text { subtype }\end{array}$ & $\begin{array}{c}\text { Gender } \\
\text { (male) }\end{array}$ & $\begin{array}{l}\text { Peripheral } \\
\text { arthritis }\end{array}$ & Enthesitis & Hip arthritis & Family histories & Waxy digitus & Iridocyclitis \\
\hline $\begin{array}{l}\text { HLA-B27- } \\
\text { negative }\end{array}$ & $11 / 11$ & $1 / 11$ & $2 / 11$ & $2 / 11$ & $2 / 11$ & $0 / 11$ & $0 / 11$ \\
\hline HLA-B* 2704 & $112 / 120$ & $73 / 120^{*}$ & $82 / 120^{*}$ & $49 / 120$ & $34 / 120$ & $1 / 118$ & $6 / 120$ \\
\hline HLA-B* 2705 & $10 / 11$ & $6 / 11$ & $6 / 11^{*}$ & $4 / 11$ & $3 / 11$ & $1 / 11^{\#}$ & $2 / 11$ \\
\hline HLA-B ${ }^{*} 2715$ & $3 / 3$ & $2 / 3$ & $2 / 3$ & $0 / 3$ & $2 / 3$ & $0 / 3$ & $0 / 3$ \\
\hline
\end{tabular}

Note: (1) data in the table for each index number of positive cases and total cases; $(2)^{*}$ comparison between groups of different B27 subtypes and group of B27negative, $P<0.01$; $(3)^{\#}$ comparison between HLA-B ${ }^{*} 2705$ and HLA-B ${ }^{*} 2704$ group, $P<0.05$.

TABLE 4: Comparison of clinical features between JAS and AAS groups.

\begin{tabular}{lccc}
\hline & JAS & AAS & $P$ \\
\hline Gender (male) & $136 / 145(93.79 \%)$ & $306 / 360(85.00 \%)$ & $\mathbf{0 . 0 0 7}$ \\
Peripheral arthritis & $82 / 145(56.55 \%)$ & $87 / 310(28.06 \%)$ & $<\mathbf{0 . 0 0 1}$ \\
Enthesitis & $92 / 145(63.45 \%)$ & $155 / 310(50.00 \%)$ & $\mathbf{0 . 0 0 3}$ \\
Hip arthritis & $55 / 145(37.93 \%)$ & $61 / 305(20.00 \%)$ & $<\mathbf{0 . 0 0 1}$ \\
Family histories & $41 / 145(28.28 \%)$ & $63 / 310(20.32 \%)$ & 0.086 \\
Waxy digitus & $2 / 143(1.40 \%)$ & $8 / 231(3.46 \%)$ & 0.230 \\
Iridocyclitis & $8 / 145(5.52 \%)$ & $26 / 310(8.39 \%)$ & 0.417 \\
\hline
\end{tabular}

a group of AAS patients showed that the onset age of patients with HLA-B27-positive was less than that in those with HLAB27-negative [8]. Both of the two studies above showed the important role of HLA-B27 in the pathogenesis of AS. A lot of evidence illuminated that HLA-27 directly participated in the pathogenesis of AS, and the direct evidence was from the study of transgenic rats, in which human B27 gene was inserted into rats; then symptoms similar to AS appeared in the transgenic rats; and the more gene replication fragment of $\mathrm{B} 27$ in rats, the more obvious symptoms [9]. As the ancestor subtype, HLA-B* 2705 was most common type in Europe and America, so most basic researches including gene cloning and transgenic animals were about HLA-B* 2705 subtype. As for HLA-B*2704 and HLA-B*2715 subtypes, our research focused mainly on clinical aspects; further basic researches are still needed, so as to explore the pathogenesis and to find new methods of diagnosis and treatment.

The onset ages of the three patients with HLA-B ${ }^{*} 2715$ were 5,9 , and 13 years and were significantly earlier than HLA-B ${ }^{*} 2704$, HLA-B ${ }^{*} 2705$, and B27-negative group; meanwhile the duration of HLA-B* 2715 group was longer than that of HLA-B*2705 and B27-negative groups. As a rare subtype, HLA-B ${ }^{*} 2715$ was first reported in 2001 and only found in Asia $[10,11]$, and there were no more than 20 cases found so far in our previous study $[7,8]$; most of them were AS patients. Six sporadic cases were found in present research, and three of them were JAS patients with early onset age, indicating that this subtype was related to the disease.

There were significant difference in male ratio, peripheral arthritis, enthesitis, and hip arthritis in JAS than AAS patients with HLA-B ${ }^{*} 2704$ (shown in Table 5). The different phenotypes in juvenile and adult patients with the same subtype showed the complexity of AS pathogenesis. The study about pedigree and twins showed the multigenic mode of AS hereditary susceptibility. Hence, the difference between JAS and AAS with the same B27 subtype may be related to other genes and the different genetic expression of B27 under the influence of environment. As HLA-B*2704 is the predominant subtype in Han population [7], the numbers of patients in HLA-B ${ }^{*} 2705$ and HLA-B ${ }^{*} 2715$ groups were small. There were no significant difference in male ratio, peripheral arthritis, enthesitis, and hip arthritis between JAS and AAS patients with HLA-B ${ }^{*} 2705$, and this was not consistent with 
TABLE 5: Comparison of clinical features in JAS and AAS patients with HLA-B ${ }^{*} 2704$ and B* 2705.

\begin{tabular}{|c|c|c|c|c|c|c|}
\hline & \multicolumn{3}{|c|}{ HLA-B* 2704} & \multicolumn{3}{|c|}{ HLA-B* 2705} \\
\hline & JAS & AAS & $P 1$ & JAS & AAS & $P 2$ \\
\hline Gender (male) & $112 / 120(93.33 \%)$ & $237 / 275(86.18 \%)$ & 0.042 & $10 / 11(90.91 \%)$ & $33 / 38(86.84 \%)$ & 0.720 \\
\hline Peripheral arthritis & $73 / 120(60.83 \%)$ & $65 / 238(27.31 \%)$ & $<0.001$ & $6 / 11(54.54 \%)$ & $14 / 37(37.84 \%)$ & 0.329 \\
\hline Enthesitis & $82 / 120(68.33 \%)$ & $114 / 238(47.90 \%)$ & $<0.001$ & $6 / 11(54.54 \%)$ & $24 / 37(64.86 \%)$ & 0.539 \\
\hline Hip arthritis & $49 / 120(40.83 \%)$ & $48 / 241(19.92 \%)$ & $<0.001$ & $4 / 11(36.36 \%)$ & $5 / 32(15.62 \%)$ & 0.303 \\
\hline Family histories & $34 / 120(28.33 \%)$ & $54 / 238(22.69 \%)$ & 0.207 & $3 / 11(27.27 \%)$ & 7/37 (18.92\%) & 0.553 \\
\hline Waxy digitus & $1 / 118(0.85 \%)$ & 7/177 (3.95\%) & 0.161 & 1/11 (9.09\%) & $0 / 27$ & 0.117 \\
\hline Iridocyclitis & $6 / 120(0.05 \%)$ & $21 / 238(8.82 \%)$ & 0.385 & 2/11 (18.18\%) & $3 / 37(8.11 \%)$ & 0.342 \\
\hline
\end{tabular}

many studies in Caucasians [12, 13]; our results should be further estimated in larger samples.

Our study showed that hip involvement was more common in JAS than AAS (shown in Tables 4 and 5); this was similar to the studies in China, Taiwan, and India $[3,6]$, and there was no significant difference in the B27-negative and B27-positive groups. Forty percent of patients with juvenile spondyloarthropathy progressed to functional disability in 10 to 15 years [14], and the hip involvement closely associated with poor prognosis [15]. Recent researches show that abnormality of bone loss can appear in early spondyloarthropathies and JAS; hip BMD significantly negatively correlated with BASDAI $[16,17]$. These findings emphasize the need for more alertness for hip involvement at an early stage of JAS.

\section{Conclusions}

Our study showed that JAS patients with different B27 subtypes had similar features in most of manifestations, and JAS and AAS with the same subtype could have distinctive courses. Therefore, early diagnosis, hip detection, and control of systemic active inflammation will be helpful for improving the prognosis of JAS patients.

\section{Conflict of Interests}

The authors declare that there is no conflict of interests regarding the publication of this paper.

\section{Authors' Contribution}

Yikun Mou and Pingping Zhang contributed equally.

\section{Acknowledgments}

This work was supported by the 5010 Subject of Sun Yat-Sen University (2007023) and National Natural Science Foundation of China Grant (31070806).

\section{References}

[1] D. A. Brewerton, F. D. Hart, A. Nicholls, M. Caffrey, D. C. James, and R. D. Sturrock, "Ankylosing spondylitis and HL-A 27," The Lancet, vol. 1, no. 7809, pp. 904-907, 1973.
[2] L. Schlosstein, P. I. Terasaki, R. Bluestone, and C. M. Pearson, "High association of an HL-A antigen, W27, with ankylosing spondylitis," The New England Journal of Medicine, vol. 288, no. 14, pp. 704-706, 1973.

[3] Y.-C. Lin, T.-H. Liang, W.-S. Chen, and H.-Y. Lin, "Differences between juvenile-onset ankylosing spondylitis and adult-onset ankylosing spondylitis," Journal of the Chinese Medical Association, vol. 72, no. 11, pp. 573-580, 2009.

[4] G. Y. Shi, "Early clinical characteristic of juvenile-onset spondyloarthropathies," Chinese Journal of Rheumatology, vol. 3, no. 3, pp. 131-132, 1999.

[5] M. Stone, R. W. Warren, J. Bruckel, D. Cooper, D. Cortinovis, and R. D. Inman, "Juvenile-onset ankylosing spondylitis is associated with worse functional outcomes than adult-onset ankylosing spondylitis," Arthritis Care and Research, vol. 53, no. 3, pp. 445-451, 2005.

[6] A. Aggarwal, P. Hissaria, and R. Misra, "Juvenile ankylosing spondylitis-is it the same disease as adult ankylosing spondylitis?" Rheumatology International, vol. 25, no. 2, pp. 94-96, 2005.

[7] Y. Mou, Z. Wu, J. Gu et al., "HLA-B27 polymorphism in patients with juvenile and adult-onset ankylosing spondylitis in Southern China," Tissue Antigens, vol. 75, no. 1, pp. 56-60, 2010.

[8] Z. Wu, Z. Lin, Q. Wei, and J. Gu, "Clinical features of ankylosing spondylitis may correlate with HLA-B27 polymorphism," Rheumatology International, vol. 29, no. 4, pp. 389-392, 2009.

[9] M. Breban, C. Hacquard-Bouder, and G. Falgarone, "Animal models of HLA-B27 associated diseases," Current Molecular Medicine, vol. 4, no. 1, pp. 31-40, 2004.

[10] S. García-Fernández, S. Gonzalez, A. M. Blanco et al., "New insights regarding HLA-B27 diversity in the Asian population," Tissue Antigens, vol. 58, no. 4, pp. 259-262, 2001.

[11] C. E. M. Voorter, W. T. N. Swelsen, and E. M. van Den Berg-Loonen, "HLA-B* 27 in molecular diagnostics: Impact of new alleles and polymorphism outside exons 2 and 3," Tissue Antigens, vol. 60, no. 1, pp. 25-35, 2002.

[12] F. D. O'Shea, E. Boyle, R. Riarh, S. M. Tse, R. M. Laxer, and R. D. Inman, "Comparison of clinical and radiographic severity of juvenile-onset versus adult-onset ankylosing spondylitis," Annals of the Rheumatic Diseases, vol. 68, no. 9, pp. 1407-1412, 2009.

[13] S. Ozgocmen, O. Ardicoglu, A. Kamanli et al., "Pattern of disease onset, diagnostic delay, and clinical features in juvenile onset and adult onset ankylosing spondylitis," Journal of Rheumatology, vol. 36, no. 12, pp. 2830-2833, 2009.

[14] B. Flatø, A. Aasland, O. Vinje, and Ø. Førre, "Outcome and predictive factors in juvenile rheumatoid arthritis and juvenile 
spondyloarthropathy," The Journal of Rheumatology, vol. 25, no. 2, pp. 366-375, 1998.

[15] L. Gensler and J. C. Davis Jr., "Recognition and treatment of juvenile-onset spondyloarthritis," Current Opinion in Rheumatology, vol. 18, no. 5, pp. 507-511, 2006.

[16] M. A. C. van der Weijden, J. C. van Denderen, W. F. Lems, M. W. Heymans, B. A. C. Dijkmans, and I. E. van der Horst-Bruinsma, "Low bone mineral density is related to male gender and decreased functional capacity in early spondylarthropathies," Clinical Rheumatology, vol. 30, no. 4, pp. 497-503, 2011.

[17] J. Bao, Y. Chen, and Y.-X. Bao, "Prevalence and risk factors of low bone mineral density in juvenile onset ankylosing spondylitis," Calcified Tissue International, vol. 95, no. 2, pp. 108-111, 2014. 


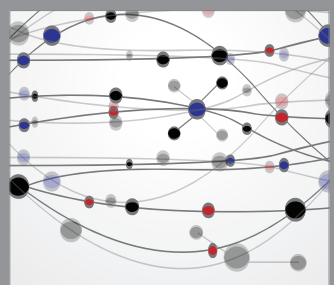

The Scientific World Journal
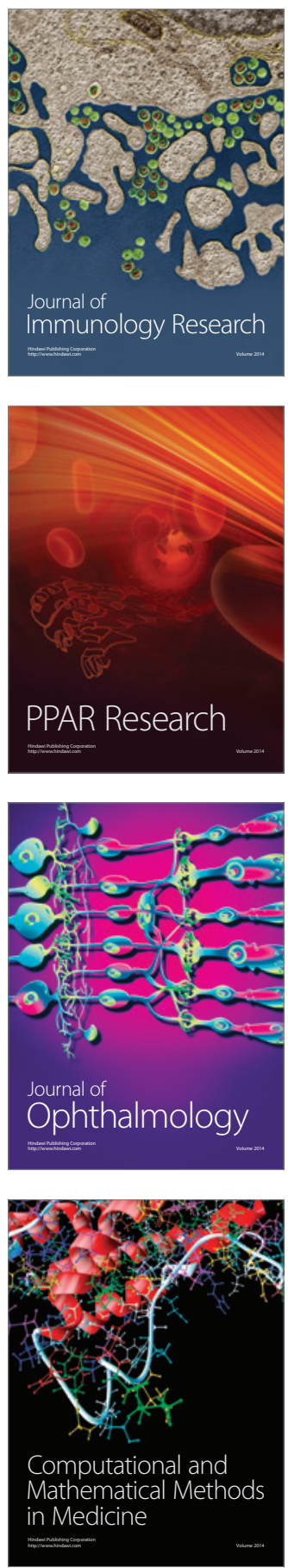

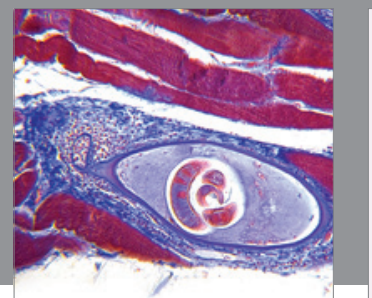

Gastroenterology

Research and Practice
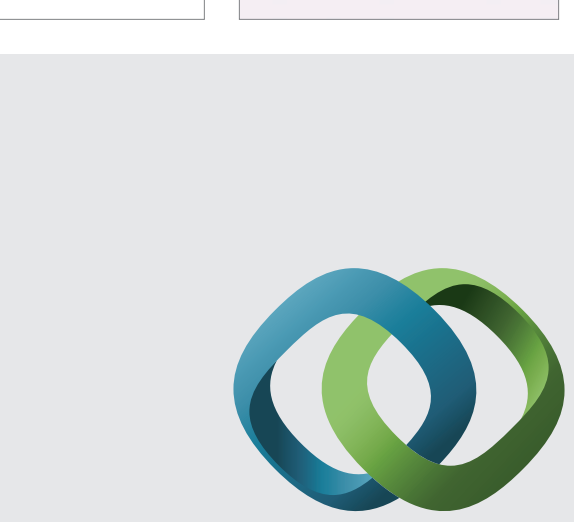

\section{Hindawi}

Submit your manuscripts at

http://www.hindawi.com
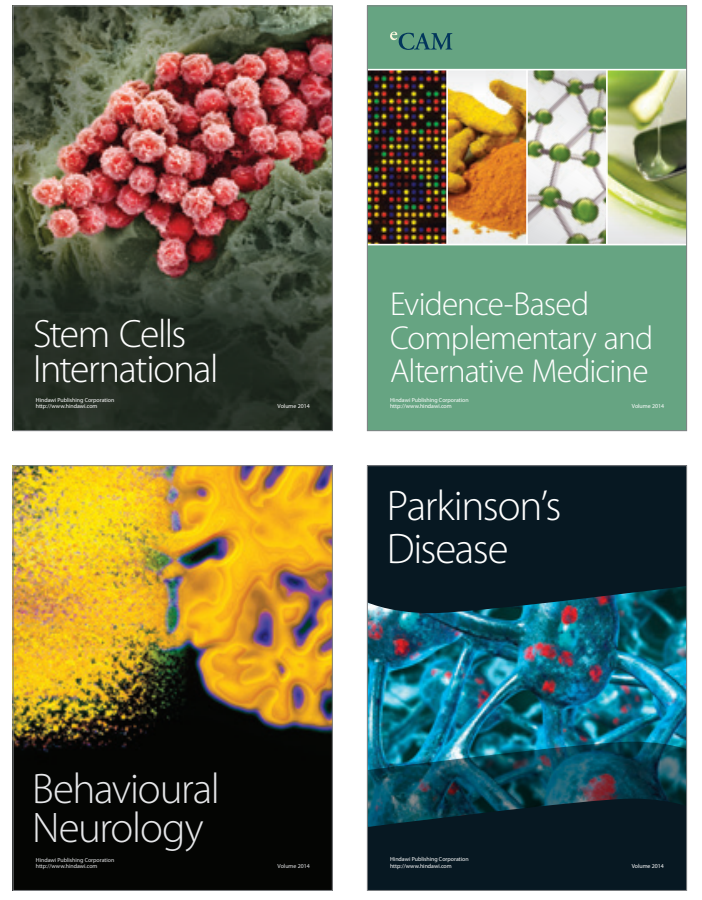
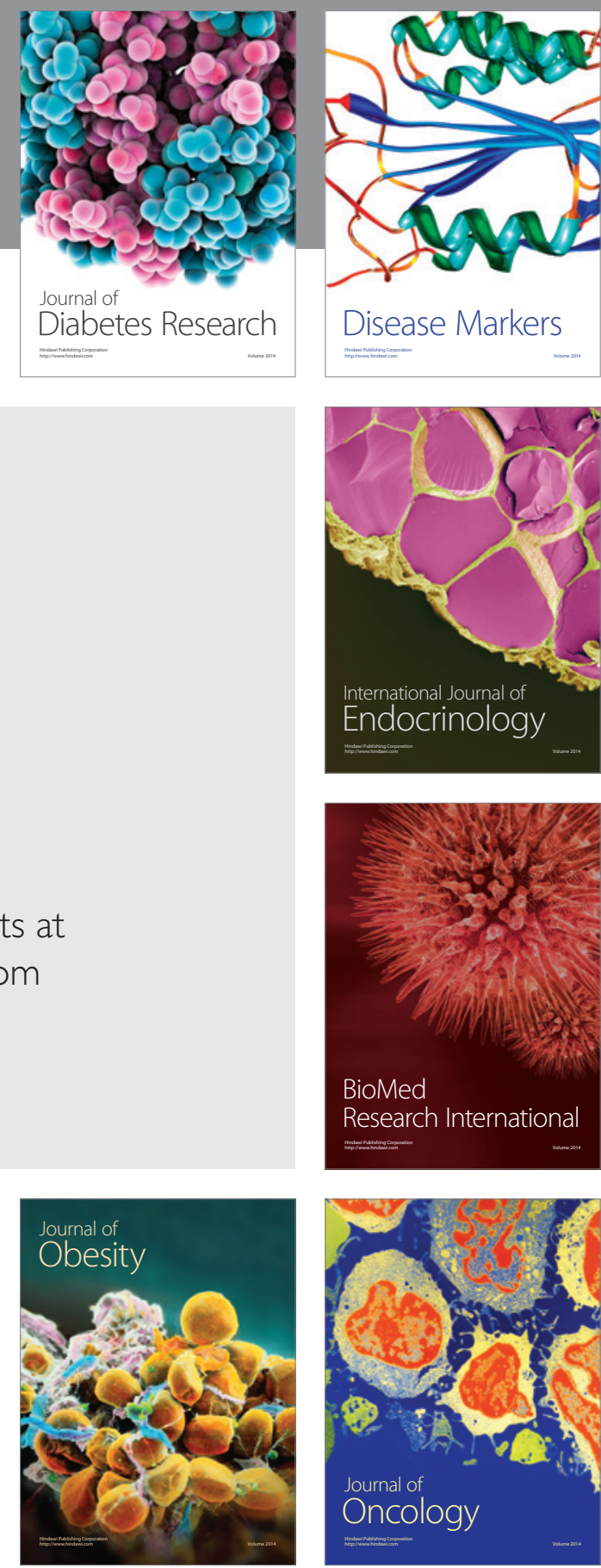

Disease Markers
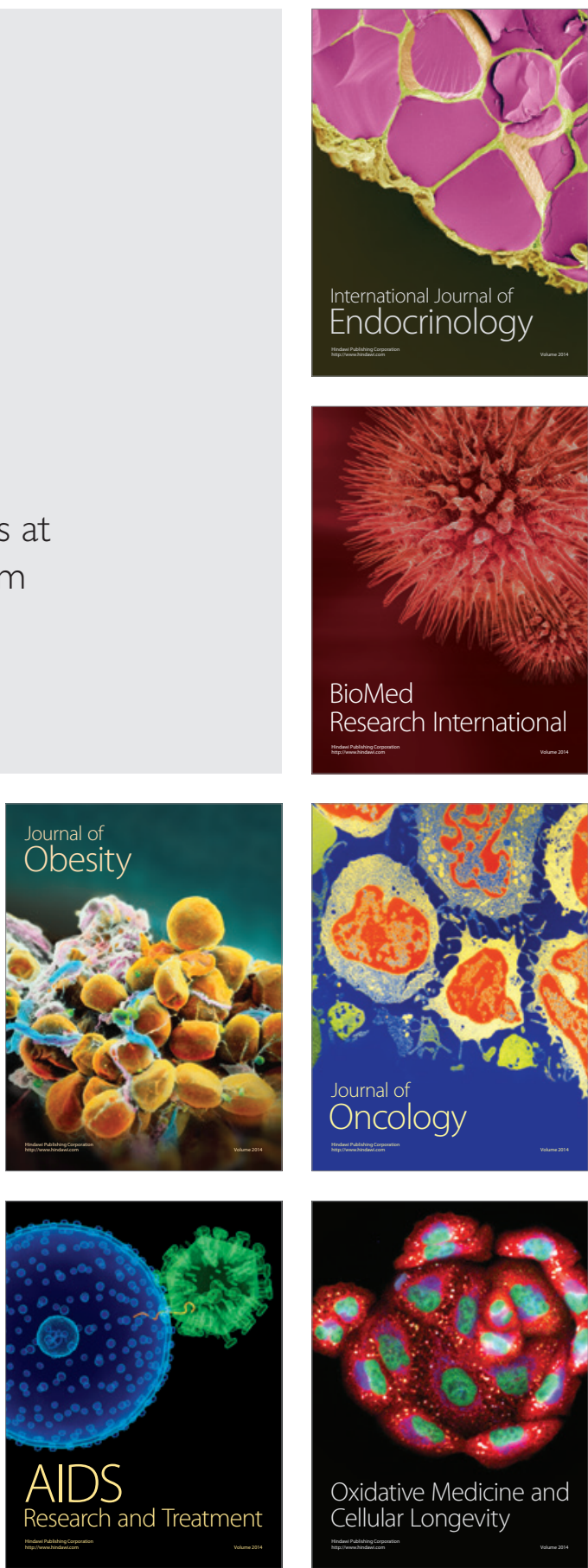